\title{
A representação da imigração haitiana no Vale do Taquari/RS a partir do jornal O Informativo do Vale (2012-2017)
}

\author{
The representation of haitian immigration in the Valley of Taquari/ \\ RS from the newspaper O Informativo do Vale (2012-2017)
}

\author{
Willian Henrique Hoppe ${ }^{1}$ \\ Universidade do Vale do Taquari, Lajeado, RS, Brasil.
}

Mateus Dalmaz ${ }^{2}$

Universidade do Vale do Taquari, Lajeado, RS, Brasil.

\begin{abstract}
Resumo: O objetivo deste artigo é compreender a representação simbólica sobre imigração haitiana para o Vale do Taquari/RS no jornal O Informativo do Vale, de Lajeado/RS. Qual o discurso elaborado pelo O Informativo do Vale? A hipótese perseguida é a de que o periódico desenvolve um discurso cultural e também econômico. O recorte temporal estabelecido é voltado aos anos de 2012 até o final de 2017, tendo em vista a onda migratória do período. O destino foi escolhido levando em consideração uma série de variáveis, entre elas, a cultura e a oferta de condições de trabalho, sendo que o Vale do Taquari se tornou atrativo, uma vez que várias empresas, especialmente do ramo alimentício e da construção civil, encontravam dificuldades na contratação de mão de obra. A metodologia utilizada é a qualitativa, a partir da análise das matérias publicadas pelo periódico de maior circulação regional, além de revisão bibliográfica e levantamento de dados a partir das reportagens. Inicialmente, é abordado o referencial teórico. Em seguida, é feita a caracterização do jornal enquanto empresa jornalística. Por fim, é elaborada uma análise sobre a representação simbólica da imigração haitiana nas matérias do periódico.
\end{abstract}

Palavras-chave: Imprensa. Representação simbólica. Imigração.

\begin{abstract}
The purpose of this article is to understand the symbolic representation of Haitian immigration to the Taquari Valley/RS in the newspaper O Informativo do Vale, Lajeado/RS. What is the speech made by the Vale Newsletter? The hypothesis pursued is that the journal develops a cultural as well as an economic discourse. The time frame established is focused on the years 2012 until the end of 2017, considering the migratory wave of the period. The destination was chosen taking into account a number of variables, including culture and the provision of working conditions, and the Taquari Valley became attractive, as several companies, especially in the food and construction industry, found difficulties in hiring labor. The methodology used is qualitative, based on the analysis of the articles published by the journal with the largest regional circulation, as well as the literature review and data collection from the reports. Initially, the theoretical framework is addressed. Then, the newspaper is characterized as a journalistic company. Finally, an analysis is made of the symbolic representation of Haitian immigration in the periodicals.
\end{abstract}

Keywords: Press. Symbolic representation. Immigration.

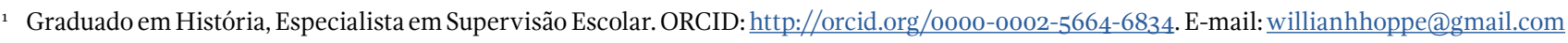

2 Doutor em História. ORCID: http://orcid.org/0000-0001-9929-4325. E-mail: mateusdalmaz@gmail.com
} 


\section{Introdução}

A Região do Vale do Taquari/RS, assim como muitas outras do País, recebeu na última década um grande número de imigrantes haitianos. O jornal O Informativo do Vale, de Lajeado/RS, a exemplo de outros meios de comunicação social, vem publicando matérias a respeito do tema.

A presente pesquisa analisa o discurso utilizado pelo periódico para tratar da comunidade haitiana no Vale do Taquari/RS. Para isso, foram analisadas as matérias publicadas nos últimos cinco anos (2012-2017). Examinando-as, busca-se compreender os pontos de vista veiculados pelo O Informativo do Vale a respeito da chegada e a presença de haitianos na região.

O fenômeno da migração não é novidade no campo da história. As pessoas migram de um país para o outro por vários motivos, sejam eles sociais, culturais, políticos e econômicos. A forma como as pessoas nativas - do século XXI - sentem-se ao dividir espaços com pessoas de lugares diferentes e identificar a forma como a imprensa traduz esse sentimento é um dos objetivos da pesquisa.

Ainda que os fenômenos migratórios e os eventos relacionados a eles sejam o pano de fundo do trabalho, a pesquisa tem por preceito analisar o discurso aplicado pelos meios de comunicação social. Dessa maneira, o objeto de estudo não são as comunidades de imigrantes, e sim a forma como essa comunidade é caracterizada pelo O Informativo do Vale.

Logo, apresenta-se como problemática qual a imagem da imigração haitiana para o Vale do Taquari/RS nas páginas do jornal O Informativo do Vale de Lajeado/RS? A hipótese perseguida foi a de que o jornal elabora um discurso econômico, enfocando os efeitos da mão de obra haitiana na economia regional e, também, constrói um discurso cultural, salientando particularidades da comunidade haitiana inseridas na região.

\section{O jornal como representação simbólica do real}

A partir dos anos 1930, foram os consumidores e a publicidade, aliados a uma modernização técnica e empresarial, que garantiram a consolidação da fase informativa moderna no estado. Um exemplo desse processo de transição e de consolidação é o jornal Correio do Povo, fundado ainda no século XIX (1885) por Francisco Antônio Vieira Caldas Júnior. Com o objetivo de reduzir os custos e aumentar a produtividade, o periódico investiu em máquinas, tais como a primeira impressora rotativa do Rio Grande do Sul e as primeiras linotipos, o que permitiu melhorias gráficas e o aumento da sua tiragem. Na década de 1930, o Correio do Povo já tinha a supremacia no Estado, com mais de 35 mil exemplares.

De acordo com Francisco Rüdiger (2003), estabelecia-se, a partir de então, um novo regime jornalístico, onde

[...] as matérias noticiosas suplantavam os artigos políticos, e as feições gráficas adquiriam as formas que, em linhas gerais, conhecemos hoje. A circulação se ampliava consideravelmente e começava a tirania do departamento comercial sobre a redação. O pessoal envolvido na atividade se profissionalizava, transformando-se em categoria assalariada (2003, p. 69). 
Além das modificações técnicas e profissionais, um outro fator passava a ser fundamental nessa fase do jornalismo, ou seja, a publicidade que viria a ser a principal fonte de receita para os periódicos, uma vez que estes

[...] foram tomando consciência de que sua sobrevivência e progresso não poderia depender mais exclusivamente dos seus assinantes e leitores, descobrindo na prestação de serviço publicitário um significativo meio de desenvolvimento e sucesso. Em função disso, os departamentos comerciais começaram a se transformar de simples balcão de assinatura e recebimento de pequenos anúncios em verdadeiras gerências de publicidade, que providenciavam ou sugeriam a contratação de certos profissionais para a criação do material de propaganda de seus clientes (RÜDIGER, 2003, p. 45).

Esses estímulos do mercado preestabelecem alguns discursos que a instituição pode ou não adotar. Pierre Bourdieu (1997) diz que essa interação funciona como uma situação de mercado, que tem características conjunturais cujos princípios são, em primeiro lugar, um espaço previamente construído, isto é, a composição social do grupo é antecipadamente determinada com o objetivo de compreender o que pode ou não ser dito.

Para o entendimento do conceito de campo jornalístico, Bourdieu (1997) salienta que:

O campo jornalístico constituiu-se como tal, no século XIX, em torno da oposição entre os jornais que ofereciam antes de tudo "notícias" de preferência "sensacionais" ou, melhor, "sensacionalistas", e jornais que propunham análises e "comentários", aplicados em marcar sua distinção com relação aos primeiros afirmando abertamente valores de "objetividade"; ele é o lugar de uma oposição entre duas lógicas e dois princípios de legitimação: o reconhecimento pelos pares, concedido aos que reconhecem mais completamente os "valores" ou os princípios internos, e o reconhecimento pela maioria, materializando no número de receitas, de leitores, de ouvintes ou de espectadores, portanto, na cifra da venda e no lucro em dinheiro, sendo a sensação do plebiscito, nesse caso, inseparavelmente um veredito do mercado (BOURDIEU, 1997, p. 105).

Ainda segundo Bourdieu (1997), muito diferente do artístico ou do jurídico, o campo jornalístico, assim como o político e econômico, está constantemente sujeito a veredictos do mercado, seja por leitores, seja pela clientela. Os jornalistas são, dessa forma, propensos a adotar o critério do índice de audiência, isto é: fazer simples, fazer curto e, assim, atrair menos críticas do mercado.

O jornal é um instrumento que, a exemplo dos demais meios de comunicação, utiliza a linguagem como ferramenta para difundir ideias. Esse discurso é uma forma de poder simbólico, onde a circulação impressa, somada aos novos meios de textualidade eletrônica, possibilita um alcance muito grande de leitores - o que, segundo Roger Chartier (2003), transforma a maneira de organizar as argumentações, históricas ou não, e os critérios que podem mobilizar um leitor para aceitá-las ou rejeitá-las. Pierre Bourdieu (1997) trabalha os sistemas simbólicos 
como instrumentos de conhecimento e de comunicação; só podem exercer um poder estruturante porque são estruturados, ou seja, existe uma estrutura ligada ao discurso.

O conceito de cultura que emergiu no início do século XIX pode ser descrito "como o processo de desenvolvimento e enobrecimento das faculdades humanas, um processo facilitado pela assimilação de trabalhos acadêmicos e artísticos e ligado ao caráter progressista da era moderna" (THOMPSON, 1995, p. 170). Esse conceito, no entanto, é a concepção clássica de cultura, muito ligada ao cultivo de qualidades e valores voltados ao apelo a trabalhos da academia de arte. John Thompson (1995) indica que, atualmente, a cultura está menos ligada ao enobrecimento da mente e do espírito no coração da Europa e mais ligada à elucidação dos costumes, práticas e crenças de outras sociedades.

As matérias, enquanto objeto de pesquisa, são representações simbólicas da realidade e da cultura. Por conseguinte, essas interpretações da vida material são elaboradas por profissionais do jornalismo. O modo com o qual as reportagens são editadas e posteriormente interpretadas dependem de uma série de contextos sócio-históricos. Sobre a produção de formas simbólicas, Thompson (1995) diz que

os seres humanos não apenas produzem e recebem expressões linguísticas significativas, mas também conferem sentido a construções não linguísticas - ações, obras de arte, objetos materiais de diversos tipos. O caráter simbólico da vida humana tem sido um tema constante de reflexão entre as ciências humanas (THOMPSON, 1995, p. 174).

Ainda segundo Thompson (1995), o texto deve estar inserido em contextos sociais dentro dos quais e por meio dos quais ele é produzido e recebido, portanto, é inadequado desconsiderar o sentido que ele tem para os próprios indivíduos envolvidos em sua criação ou na sua interpretação.

Para tratar da tendência do jornalismo, foi utilizada a obra de Rüdiger (2003), onde são trabalhadas as diferentes fases do jornalismo gaúcho. A pesquisa tem como objetivo a análise das matérias do jornal O Informativo do Vale, fundado na década de 1970. Portanto, entre outras fases anteriores, utilizaremos, principalmente, a que o autor trata como jornalismo informativo moderno.

Quanto à análise de conteúdo, Zicman (1985) afirma que se trata de um conjunto de técnicas e instrumentos que permitem a exploração mais objetiva dos dados ou dos discursos. Esses dados são encontrados mais comumente em documentos históricos e em textos literários. Esses, por sua vez, são examinados levando-se em consideração a presença e a frequência nos textos. O objetivo, dessa maneira, é identificar semelhanças entre as diferentes matérias.

A seleção das edições que tiveram publicações envolvendo a temática, além do levantamento bibliográfico complementar, começaram no período de elaboração do projeto onde já foi iniciado o desenvolvimento da pesquisa. Para tanto, foram analisadas as edições de janeiro 2012 até dezembro de 2017. Nesse recorte temporal, foram publicadas 22 reportagens que envolvem o tema. 
O Informativo do Vale foi fundado na década de 1970, enquadrando-se no que Francisco Rüdiger (2003) caracteriza como jornalismo informativo moderno. O jornal passa a assumir uma postura empresarial, percebendo as transformações sociais e culturais em curso e, com isso, respondendo aos estímulos do mercado. Essa mudança na postura dos jornais foi percebida já na década de 1930, quando o Brasil vivia um processo de industrialização mais acentuado.

A área da comunicação nos oferece uma extensa bibliografia. A diversidade de temas e abordagens faz com que o campo de estudo seja transdisciplinar. Dessa maneira, é importante incluir a perspectiva histórica na abordagem dos assuntos. O desafio para o historiador, desse modo, é saber utilizar os meios de comunicação, no sentido de tornar os textos atrativos e compreensíveis àqueles que não são da área.

Baseados em Williams (1992), percebemos na última década um aumento significativo de estudos envolvendo a história da Imprensa, o que têm incentivado também fóruns e debates sobre a história nos meios de comunicação.

A comunicação, uma área muito abrangente, possui conceitos muito amplos, portanto, pode englobar todas as formas de interação social, - inclusive as comunicações interpessoais. Quando se considera a Comunicação como produção de sentidos socialmente compartilhados, a ideia quase se confunde com a linguagem. Partindo desse pressuposto, a história da Comunicação englobaria, além das mudanças dos meios de comunicação propriamente ditas, uma gama de outras possibilidades - estudo das transformações dos sistemas orais, da moda, da arquitetura etc. E, nesse contexto, quase se confundiria com uma história da Cultura (WILLIAMS, 1992).

Analisando as citações de Williams, percebe-se que, nas pesquisas voltadas ao campo da história da Comunicação, é necessária uma metodologia que leve em consideração a dinâmica social envolvida. Ou seja, é preciso avaliar as questões políticas e econômicas que envolvem a pesquisa.

A escolha do jornal O Informativo do Vale como objeto de pesquisa se deu pela sua presença histórica no Vale do Taquari/RS, especialmente na cidade de Lajeado/RS, no decorrer de meio século de jornalismo. A análise do discurso adotado pelo periódico permite estabelecer um panorama sobre como o diário identifica a questão da imigração - nesse caso, a imigração haitiana.

Segundo Braga (2006), além das posições ideológicas, deve se levar em consideração também as condições materiais da produção, os processos de cooperação (pois um jornal é uma obra composta), as relações concretas entre as forças em presença e as relações entre os interlocutores. Para o leitor, as condições de sua leitura intervêm na interpretação que ele faz acerca dos enunciados; para o jornalista, a condição de leitura pressupõe para o seu artigo parte de suas condições de produção.

O jornal, consequentemente, não apresenta uma posição clara e transparente, sendo necessária a interpretação

O jornal não se apresenta de si mesmo como um objeto transparente. É um enigma a resolver, é ele que nos põe questões. A pesquisa oscilará sempre entre esses dois polos: o enigma que está no objeto, enigma objetivo; e as questões que eu escolho colocar. Escolha subjetiva, mas não menos válida, porque os 
preconceitos que comandam essa escolha definem a localização do olhar do pesquisador - lugar historicamente interpretável, em consequência do qual os resultados serão mais ricos ou mais pobres, mais eficazes ou menos, desvendarão este ou aquele aspecto do objeto analisado (BRAGA, 2002, p. 331-332).

Para Elmir (1995), ao analisar textos jornalísticos, é preciso ter o máximo de cuidado para não transformar os textos-objeto da análise em instrumentos de nossos pretextos. Ainda segundo o autor, a imprensa não pode ser fonte exclusiva para qualquer pesquisa histórica. Zicman (1985) aponta que o método de análise para os discursos da imprensa deve levar em consideração a dupla substância e a natureza do próprio jornal, a sua forma e o seu conteúdo, interdependentes e interatuantes e que centre a análise no discurso de imprensa, considerando as características próprias desse tipo de escrita.

Zicman aponta, ainda, que a análise de um jornal deve levar em consideração também a administração, os editores e os colaboradores do jornal. Essa análise pode, segundo a autora, ser definida em dois grandes momentos: o primeiro seria a caracterização geral do jornal consultado e, o segundo momento, é a análise do conteúdo produzido por esse jornal.

Quanto aos procedimentos metodológicos adotados, segundo Félix (1998), os mesmos desdobram-se em quatro grandes etapas: coleta de dados, análise e interpretações dos dados, sistematização dos dados e conclusões. A coleta de dados envolve duas atividades que são concomitantes e complementares: atividade documental, que se realiza através do contato com as edições do jornal do respectivo recorte temporal, e o contato com a produção teórica historiográfica referente ao tema da pesquisa.

Além da utilização das matérias do jornal enquanto fonte de pesquisa documental e a bibliografia complementar, é utilizada a história oral para o momento e que caracterizamos o jornal. Foi realizada uma entrevista com o diretor do jornal e idealizador das ideias centrais do periódico.

Para utilização do método da história oral é importante destacar que:

um dos aspectos mais interessantes do uso de fontes orais é que não apenas se chega a um conhecimento dos fatos mas também à forma como o grupo os vivenciou e percebeu. É de importância capital resgatar a subjetividade, mas é um grave erro passar a confundi-la com fatos objetivos. Esta aproximação crítica ao testemunho oral consegue-se mediante dois procedimentos de caráter interativo: um, com a documentação escrita existente, e outro, com o resto do corpus de documentos orais. Daí a importância de se estabelecer urna relação dialética entre os diversos tipos de fontes (GARRIDO, 1992, p. 39).

Portanto, optamos pelo método da história oral apenas para caracterizar a instituição, tendo em vista a dificuldade em encontrar fontes escritas, além das matérias publicadas pelo próprio jornal que fazem alusão à vida e à trajetória do proprietário da empresa.

Com relação à pesquisa social, utilizamos novamente Thompson (1992, p. 360), que trabalha a hermenêutica na pesquisa sócio-histórica, para o autor: "os sujeitos que constituem parte do mundo social estão sempre inseridos em tradições históricas”. Mais precisamente, a herme- 
nêutica de profundidade estabelece que pesquisas onde se trabalha com um campo constituído pela força e pelo significado, é importante atribuir uma gama de métodos explanatórios.

Ainda em relação a hermenêutica, é estabelecido que o ponto de partida seja a vida cotidiana, portanto deve ser levada em consideração, primordialmente, a forma como os receptores interpretam e por quem o material é produzido. Esse percurso, por sua vez, também é interpretativo. Portanto, a forma de investigação hermenêutica pode ser dividida em três etapas: análise sócio-histórica, análise formal ou discursiva e, por fim, interpretação ou (re)interpretação.

Esclarecidas as referências teóricas e metodológicas utilizadas para elaboração desta pesquisa, reafirmam-se os seguintes cuidados: as matérias serão tratadas como formas simbólicas que são produzidas a partir de uma instituição, nesse caso, o jornal O Informativo do Vale. Parte-se, então, para a caracterização geral do periódico, fundamental para a análise da imprensa, conforme visto.

\section{Uma empresa: O Informativo do Vale}

O jornal O Informativo do Vale é o principal produto da Rede Vale de Comunicação. O diário circula em 38 municípios, sendo que 36 dessas cidades são de abrangência do Conselho de Desenvolvimento do Vale do Taquari (Codevat), além de Boqueirão do Leão e Itapuca, membros do G83. O G8 é um grupo de municípios emancipados de Lajeado/RS. A partir de 1970, década em que o jornal imprime as primeiras edições, o perfil jornalístico já é caracterizado pelo conceito de jornalismo informativo moderno, onde não existe um posicionamento claro por parte da instituição. O Informativo do Vale, enquanto empresa de comunicação, firma contratos de prestação de publicidade para os mais diversos serviços e empresas. A estrutura do jornal está posta da seguinte forma: direção, administração, redação, comercial, impressão e circulação.

\subsection{O surgimento do jornal}

O jornal foi fundado por Oswaldo Carlos van Leeuwen no dia 8 de maio de 1970. Atualmente, imprime e distribui, de segunda a sexta, oito mil exemplares em média, diariamente. Aos sábados, esse número é maior, chegando a oito mil e quinhentos exemplares.

O principal alcance do jornal está no Vale do Taquari, especialmente na cidade de Lajeado/ RS, que concentra uma população de aproximadamente 80 mil habitantes (IBGE, 2015). A partir da entrevista realizada com o diretor do jornal e com a equipe de redação, foi possível perceber que a cobertura é regional, comunitária e participativa. ${ }^{4}$

A ideia de jornalismo comunitário é no sentido de o veículo realizar coberturas de festas e eventos comunitários. Já a cobertura regional possuiu um espaço específico direcionado semanalmente, ou conforme a demanda de material que o jornal recebe das fontes dos municípios de abrangência.

\footnotetext{
3 Os municípios que compõe o G8 são: Boqueirão do Leão, Canudos do Vale, Cruzeiro do Sul, Forquetinha, Marques de Souza, Progresso, Santa Clara do Sul, Sério. Fonte: http://www.cipaeg8.rs.gov.br/site/consorcio/municipios. Acesso em: 28 maio 2018.

4 Aqui não trabalhamos o conceito de jornalismo participativo, apenas utilizamos a fala do entrevistado.
} 
Oswaldo Carlos van Leeuwen é filho de um imigrante holandês e de uma brasileira. Seu pai veio para o Brasil em decorrência da guerra que assolava a Europa. Leeuwen nasceu no dia 23 de abril de 1930 na Região serrana do Rio Grande do Sul, mais precisamente na cidade de São Francisco de Paula. Seu pai era médico, formado ainda na Europa e, logo que a sua permanência no Brasil foi reconhecida, passou a administrar o hospital da cidade onde residiam. A família esperava que Oswaldo seguisse a carreira médica. Porém, ele tinha outros objetivos, diferentes do pai, e apostou na área comercial.

Já na Região do Vale do Taquari, a família Leeuwen investiu em empresas de vários segmentos, mas foi no segmento da comunicação que encontrou mais sucesso. Em depoimento, o empresário relata que jamais teve filiação partidária. Entretanto, defende ideias "brizolistas", de esquerda. A partir dos bastidores, o proprietário conquistou respeito da comunidade e do empresariado local. Oswaldo conta que, em diversos momentos, "ajudou" na divulgação de empresas locais como forma de impulsionar a economia regional.

Credibilidade, cidadania, transparência, rapidez, comunidade, isenção, serviço, informação, entretenimento. Todos os dias o jornal ajuda a construir uma interpretação da vida, uma visão de mundo. O Informativo do Vale lhe estende, a cada novo dia, as boas-vindas a um produto sempre melhor, mais reflexivo, mais instigante, enfim, mais indispensável. O Informativo do Vale faz de você uma pessoa muito mais interessante (material publicitário do jornal, 2010).

A citação acima vai ao encontro do referencial teórico utilizado para a elaboração desta pesquisa, isto é, o jornal é uma ferramenta que representa simbolicamente a vida humana.

Uma vez elaborada a contextualização histórica relativa à fundação do jornal e apresentado o idealizador da empresa, é possível atentar-se aos aspectos jornalísticos que materializam essas ideias.

\subsection{Aspectos jornalísticos atuais}

O Informativo do Vale é um dos produtos da Rede Vale de Comunicação. As edições são impressas diariamente, de segunda-feira a sábado, quando circula com edição conjunta a de domingo. O veículo possui, aproximadamente, 8 mil assinantes, o que representa a grande maioria de sua circulação. Além disso, alguns exemplares são direcionados às bancas espalhadas por Lajeado/RS e Região.

Além da plataforma impressa, o jornal também mantém uma página na internet, onde as notícias são resumidas. Além disso, por meio da assinatura digital é possível ver, na plataforma online, todas as edições completas.

Tanto na versão impressa, quanto na online, são publicados, periodicamente, os cadernos especiais: Meio Ambiente na Escola, Estilo \& Construção, Noivas e Festas, Pura Saúde, Lazer, Classivale, Motor e Municípios. Além desses suplementos, o diário organiza material esporádico para marcar eventos, datas comemorativas, aniversários de municípios e empresas. 
A cobertura do jornal é regional, focada em um jornalismo comunitário e participativo. Isso não significa que perde o vínculo e a sintonia com o que acontece fora da Região, como no Estado, no País e no Mundo.

A disponibilização da versão online, na íntegra para os assinantes, com notícias, fotografias e anúncios é realizada em tempo real, antes mesmo do final do processo de impressão do diário. A abrangência da plataforma digital de $O$ Informativo do Vale está em constante crescimento, atingindo, atualmente, uma média de 35 mil acessos por dia. Além da versão online, a empresa também mantém uma página na rede social Facebook ${ }^{5}$, que contava, em 2018, com mais de $70^{6}$ mil seguidores.

Sobre os critérios de noticiabilidade, a definição do conteúdo que será publicado no jornal O Informativo do Vale, tanto na versão impressa, quanto na online, é feita pela equipe de editores da redação.

São os jornalistas que optam por dar maior ou menor destaque para notícia, tendo como base os critérios $^{7}$ de noticiabilidade que seguem, sem ordem de relevância:

a) abrangência da informação (quantas pessoas são impactadas com a matéria?), regionalização (acontecimentos do Vale do Taquari têm primazia, em relação aos registrados no restante do mundo);

b) ineditismo (o fato que será noticiado já aconteceu outras vezes?);

c) sensacional (o assunto tem características sensacionais, extrapola o cotidiano?). Respondendo a estas questões, a equipe escolhe o que será a manchete, que é a informação mais relevante da edição e ganha destaque, em sua área de ocupação de espaço na capa do diário. Também atende a estes critérios a escolha das matérias, que serão colocadas na parte superior das páginas internas do jornal. O mesmo vale para as fotos.

Em relação às imagens há, no entanto, um critério adicional, ou seja, são priorizadas, atendendo a uma necessidade do mercado (através da percepção da equipe), aquelas que mostram pessoas. A política editorial do jornal O Informativo do Vale, entende que o veículo deve contar histórias de pessoas e, portanto, mostrá-las para os demais leitores. Evidentemente que, casos em que a arquitetura (positiva ou negativamente) for o motivo da existência da notícia, e outros casos específicos são tratados de forma particular.

Soma-se aos critérios de noticiabilidade os resultados apurados por pesquisa interna da instituição, que levantou ser o leitor médio do jornal $O$ Informativo do Vale uma mulher, entre 25 e 34 anos, com Ensino Médio em curso ou completo, e renda entre dois e cinco salários-mínimos nacionais. Essa pessoa procura as notícias da editoria Geral, trabalhada, atualmente, nas páginas do diário em duas formas: as de Lajeado/RS e as da Região (que repercutem acontecimentos dos 37 municípios, que integram a área de abrangência do jornal). As pesquisas internas são realizadas sistematicamente pela empresa.

\footnotetext{
Disponível em: https://pt-br.facebook.com/jornaloinformativo/. Acesso em: 12 de nov. 2019.

6 Dado atualizado no fechamento deste artigo

Critérios foram fornecidos pela equipe do jornal e esquematizados pelos autores.
} 


\subsection{A estrutura}

O jornal circula de forma periódica em 37 municípios do Vale do Taquari - sendo 36 efetivamente da Região, mais Itapuca, que é noticiada por integrar o grupo econômico das cidades da parte alta do Vale, conhecido como G10. Para garantir essa cobertura de forma mais efetiva, a empresa conta com sucursal em Encantado, outro jornal em Arroio do Meio, que atende Arroio do Meio, Travesseiro e Capitão, circulando com quatro páginas diárias dessa microrregião e o restante do que é distribuído a todos os assinantes; agente em Marques de Souza; agente em Fazenda Vilanova; além de representantes comerciais em, praticamente, todas as cidades atendidas - que possibilitam a logística de entrega.

Na sede do jornal O Informativo do Vale, na Avenida Benjamin Constant, 2.197, Bairro Florestal, em Lajeado/RS, funcionam os setores: redação, comercial, arte (responsável por fazer anúncios de clientes que não têm agências e institucionais), classificados, administração, recursos humanos, assinaturas, impressão (que é feita de forma própria, por meio de rotativa com capacidade para imprimir mais de 20 mil exemplares por hora), e circulação (para Lajeado/RS e cidades próximas).

A redação, responsável pelo conteúdo jornalístico é integrada por 17 jornalistas (incluindo duas estagiárias) e três diagramadores (responsáveis pela editoração do conteúdo produzido pelos jornalistas nas páginas). Cada um deles trabalha a carga horária pertinente à função (30 horas por semana) e são remunerados (à exceção dos estagiários) conforme o piso da categoria no Estado. O critério de contratação é a vinculação com o Vale do Taquari/RS, reforçando as características regionais. Não havendo enquadramento de banco de recursos humanos, são contatados aqueles que se identificam com o jornalismo comunitário.

A administração da redação é de forma dividida, ficando um editor com a responsabilidade de produzir a pauta (que são os conteúdos que serão abordados pelos jornalistas no dia seguinte) e outro com a responsabilidade de fazer o "fechamento do jornal", que é verificar as matérias e todos os demais conteúdos a partir do momento que chegam às páginas. É esse profissional que liberará as páginas para impressão no parque gráfico.

A administração da empresa é realizada entre a família, detentora da empresa desde a sua fundação - encabeçada por Oswaldo Carlos van Leeuwen - e por um conselho administrativo, integrado pela gerente Administrativa, a gerente de Mercado e a Diretora, esposa de Oswaldo Carlos, Ivone Villa. Cada setor, no entanto, tem um responsável, que faz atualizações periódicas sobre desempenho à direção.

Os insumos, como papel, tinta e chapas de metal, onde é gravado o conteúdo para ser encaminhado à rotativa, são importados. A empresa mantém uma área fechada, em Porto Alegre, com depósito de papel, haja vista as bobinas ocuparem muito espaço e a organização se permitir fazer estoque amplo, garantindo menor preço e condições de negociabilidade.

O jornal O Informativo do Vale surgiu a partir da vontade de um empreendedor que viu na área da Comunicação um mercado em expansão. Depois de consolidado regionalmente, o jornal passou a acentuar a sua ação enquanto meio de comunicação. Hoje, o jornal apresenta, simbolicamente, a "vida” da Região do Vale do Taquari/RS aos seus leitores. 
A análise das 23 matérias a seguir, observa a maneira como o jornal apresenta a inserção da comunidade haitiana no Vale do Taquari/RS e, a partir disso é possível estabelecer elos entre o discurso do jornal e a temática envolvida.

\section{Sonhos e expectativas}

No Bairro Moinhos, em Lajeado/RS, Simon, a esposa e os dois filhos se ambientam em Lajeado/RS. O varal cheio de roupas denuncia que Victolene é dada à lida doméstica. Simon deixou pai, mãe e amigos no Haiti. Gosta daqui mas sonha um dia em ser mestre. Constituir um bom padrão de vida e quiçá retornar ao seu país de origem: "A casa onde a gente mora é muito boa. Tudo é bom aqui, poderíamos ganhar um pouco mais, mas isso também é uma questão de tempo", acredita Simon (O INFORMATIVO, 2015)).

Os sonhos e expectativas da comunidade haitiana no Vale do Taquari/RS também são representados nas páginas do O Informativo do Vale. essa seção objetiva analisar a representação simbólica da inserção dos imigrantes haitianos em questões culturais da Região. Procura-se identificar como o jornal expressa a forma através da qual a população recebe os estrangeiros em questão e como estão envolvendo-se no dia a dia do Vale.

A língua portuguesa ainda continua sendo um dos principais desafios para os imigrantes haitianos, cuja problemática é percebida desde 2013, quando o número de haitianos no Vale ainda era muito mais modesto. Em 27 de outubro de 2013, O Informativo do Vale publicou matéria envolvendo esse tema, com o título: "Voluntário ensina haitianos falar português em Lajeado/RS”. A matéria destaca o voluntariado do haitiano Renel Simon que na época residia há dois anos no Brasil (INFORMATIVO, 2013).

Segundo a matéria, Simon teve facilidade em aprender a falar português e toda essa facilidade fez com que ele tomasse a iniciativa de ensinar aos seus conterrâneos, que assim como ele, deixaram o Haiti na esperança de ter uma boa oportunidade de emprego. As aulas de português foram oferecidas nas dependências da Casa de Cultura de Lajeado/RS e as primeiras edições tiveram participação de 25 haitianos. Cada aula tinha, em média, 2h30. A matéria destaca a necessidade da língua, especialmente, por uma questão de inserção no mercado de trabalho (INFORMATIVO, 2013).

A língua é apenas uma das diferenças culturais que distanciam os imigrantes da população do Vale do Taquari. Percebendo o aumento da população negra no Vale, em 2014 O Informativo trabalhou a questão publicando matéria que visa a refletir sobre as questões raciais. A matéria traz dados do Censo Demográfico de 2010, que indicava que cerca de 8,6 mil pessoas do Vale do Taquari consideram-se negras, o que representava apenas 2,5\% da população. Hoje [2014], soma-se a esse número cerca de 4,4 mil imigrantes, haitianos, senegaleses, nigerianos e ganeses. Isso desenha um novo cenário de miscigenação no Vale do Taquari, que viu a população negra crescer em torno de $50 \%$. Essa vinda se dá especialmente pela oferta de emprego (INFORMATIVO, 2014).

A vinda dos haitianos ao Vale do Taquari é uma forma de mostrar a situação em que os negros do País se encontram, onde, através desse panorama, é possível refletir acerca da importância que 
possuem na história, na cultura e na economia do Brasil. Nesse contexto, é possível salientar também que valorizar a identidade negra é relevante para que se construa a identidade étnica da nação.

O Haiti possui cerca de $95 \%$ da população negra, sendo o primeiro país negro do mundo a declarar a independência. Esse é um grande motivo de orgulho para os haitianos que residem em solo brasileiro hoje. As maiores barreiras dos imigrantes são em relação à língua portuguesa, onde há uma grande dificuldade de comunicação até que ocorra o processo de adaptação ao idioma. E, além disso, torna-se difícil conseguir moradia, uma vez que alugar um imóvel requer fiadores. Segundo Simon, essa é uma forma de preconceito (INFORMATIVO 2014).

Embora grande parte dos haitianos trabalhem em frigoríficos e na construção civil, Daniel Granada (2014) afirma que os empreendedores do Vale devem prestar atenção no potencial dos imigrantes, pois muitos cursaram Ensino Superior e falam mais de um idioma. É necessário ter a visão de que são pessoas que vieram com o intuito de contribuir com o Vale. Dessa forma, investir nas qualidades e nas capacidades desses profissionais é uma característica que se enquadra na história do Vale do Taquari, marcada por imigrantes italianos e alemães (INFORMATIVO 2014).

Granada salienta também em sua fala que receber e acolher bem os imigrantes negros não é responsabilidade dos afrodescendentes apenas e sim de toda a sociedade, independentemente de cor, raça ou etnia, pois é imprescindível o reconhecimento e a valorização dos negros, uma vez que possuem grande importância e fazem parte da história no Brasil (INFORMATIVO, 2014).

No Brasil há oito anos, o haitiano Pierre Dieucel, vigário da igreja matriz da cidade de Encantado, conta que foi muito bem acolhido pela população encantadense. Porém, pondera que não é a sensação que os demais haitianos têm. Na entrevista concedida ao jornal, o padre indica que os imigrantes recebem ajuda, porém é necessário fazer com que se sintam de fato acolhidos.

A matéria utiliza um espaço significativo para falar sobre a exclusão social sistemática que ocorre no Brasil. No subtítulo "A elite branca ainda permanece”, o coordenador da Área de Humanidades da Universidade do Vale do Taquari - UNIVATES, Daniel Granada, explica que, apesar de avanços, manteve-se a escala hierárquica da sociedade brasileira, na qual os negros ocupam a base. Para mudar esse quadro são necessárias mudanças sociais que garantam acesso à educação, à saúde e ao mercado de trabalho. A reportagem finaliza apontando os altos índices de violência, dizendo que os homens jovens negros são os que mais morrem de forma violenta (INFORMATIVO, 2014).

Ainda com relação ao preconceito, em 2 de fevereiro de 2015, o Informativo volta a dar espaço ao tema quando publica matéria intitulada: "Imigrantes enfrentam preconceitos ao se adaptarem à vida no Sul”. A matéria dá conta da falta de oportunidades de estudo para população imigrante. O Brasil é destino escolhido por muitos procurando emprego e acesso à graduação por meio de financiamentos, porém não é o que encontram. Sobram, portanto, trabalhos braçais, os chamados “chão de fábrica”. Outro dado é que as empresas optam pela mão de obra haitiana apenas quando não têm outra opção, pela mão de obra escassa (para esse tipo de função) no Vale do Taquari, o que não deixa de ser uma forma de preconceito e discriminação, somado à diferença de tratamento dado pela administração das empresas para colaboradores haitianos em relação aos demais (INFORMATIVO, 2015). 
Por outro lado, existe um forte tensionamento no sentido de inserir os haitianos na cultura do Vale. Uma dessas iniciativa é o Haiti Cultural. A ação, elaborada pela Rádio da Univates, disponibiliza espaço à cultura haitiana aos sábados. No dia 15 de julho de 2015, O Informativo do Vale divulgou a iniciativa que surgiu por meio de lideranças da comunidade haitiana local. A rádio da Univates iniciou o projeto abrindo a programação a professores da área de humanidades (da Univates), eles falaram sobre projetos de pesquisa desenvolvidos pela instituição. O objetivo é promover a integração dos haitianos na comunidade do Vale do Taquari a partir do conhecimento sobre a história e a cultura do país, promovendo também sua melhor integração na sociedade (INFORMATIVO, 2015).

Além da língua, existem outras questões de cunho cultural, a fé é uma dessas questões. A grande maioria dos imigrantes haitianos são ligados à Igreja Evangélica Cruzada Pentecostal Brasileira. Os casais de haitianos, segundo matéria publicada em 10 de outubro de 2015, têm como regra apenas dividir uma residência quando casados formalmente. A formalização do matrimônio nem sempre é um processo simples, tendo em vista a necessidade de documentos expedidos pela embaixada haitiana no Brasil. O casal Marcelene Octavius e Kerssaint Adme, conquistaram o direito ao matrimônio por via judicial. O magistrado Luís Antônio de Abreu Johnson, da comarca de Lajeado/RS, deferiu o pedido de validação do casamento.

A partir da análise das matérias é possível perceber alguns tensionamentos no sentido de haver maior intercâmbio cultural. Dois exemplos disso foram publicados no O Informativo do Vale nos dias 7 de dezembro de 2015 e 11 de janeiro de 2016.

Com o objetivo de incentivar o intercâmbio cultural, o curso de Letras da Univates promoveu um encontro multicultural. Nesse dia, aconteceram manifestações artísticas, roda de capoeira, apresentação de dança e música. A capoeira é uma prática que não é comum no Haiti. Outra ação nesse sentido aconteceu quando o Sindicato do Trabalhadores nas Indústrias Avícolas e Alimentação em Geral de Lajeado/RS e Região (STIAL), promoveu um campeonato de futebol sete. Uma das equipes que participaram era formada por imigrantes haitianos que trabalham nas indústrias desse segmento.

Essa integração dos haitianos foi tema de um documentário intitulado: Haitianos: na esperança de um novo dia (2016). A produção é do grupo Diaconia da Comunidade Evangélica de Lajeado/RS. O projeto surgiu no início do ano de 2016 e teve como objetivo realizar ações para acolher esses imigrantes, por meio de palestras, encontros e o vídeo. No documentário, os imigrantes tiveram espaço para falar dos desafios que enfrentam no dia a dia do Vale, alguns desses desafios são o preconceito, a falta de oportunidade para estudar e a falta de segurança (INFORMATIVO, 2016).

\subsection{Iniciativas do poder público em relação aos haitianos}

O aumento significativo do número de imigrantes haitianos no Vale do Taquari fez com que o poder público também reagisse ao estímulo de setores da iniciativa privada. Nesse sentido, aconteceram algumas programações voltadas ao público haitiano. Um desses eventos foi organizado pela Prefeitura de Lajeado/RS, por meio da Secretaria de Trabalho Habitação e Assistência Social (STHAS), onde foram oferecidas atrações esportivas, recreativas e ações de orientação. Lajeado/RS possuía na época [2014], cerca de 500 haitianos (INFORMATIVO, 2014). 
A matéria publicada pelo O Informativo do Vale em 7 de julho de 2014, indica que não havia integração entre o lazer da comunidade do Vale e os recém-chegados haitianos. A intenção da Prefeitura, segundo a matéria era de fazer com que essas pessoas se sentissem pertencentes a cidade, como qualquer outro cidadão do Vale do Taquari. Ainda nesse sentido a STHAS fez um trabalho para incluir as famílias haitianas no Cadastro Único do Governo Federal, a fim de terem acesso a benefícios sociais do governo.

Para o então prefeito de Lajeado/RS, Luís Fernando Schmidt ${ }^{8}$, existe uma obrigação humanitária da administração com relação aos haitianos: "O Brasil já foi importante no Haiti e queremos ter essa importância, mas também que os haitianos tenham importância para nós” (INFORMATIVO, 2014).

Já em relação ao nível estadual, representantes da prefeitura de Lajeado/RS estiveram reunidos com representantes de entidades como a Fundação Gaúcha do Trabalho e Ação Social (FGTAS) e o Secretário Estadual de Trabalho e do Desenvolvimento Social do Rio Grande do Sul. O objetivo da reunião que ocorreu em Lajeado/RS no dia 14 de agosto de 2015, foi de estabelecer estratégias para bem assistir esses imigrantes, especialmente, na questão do emprego e da assistência social. A matéria indica que Lajeado/RS e Região se destacam não só pela questão do emprego, mas também pelas políticas assistenciais adotadas pelos governos locais. Uma preocupação em âmbito estadual é a questão da rapidez em viabilizar a documentação e a oferta de cursos de português. Sobre a questão burocrática, como já mencionado anteriormente, a questão do casamento se coloca como um fator essencial na cultura haitiana. Nesse sentido, o haitiano Simon declara:

Existe algumas questões que na nossa cultura é fundamental, como o casamento. No Brasil, enfrentamos várias burocracias para casar e isto nos prejudica culturalmente." [...] Aqui as autoridades estão próximas da gente e juntos podemos facilitar o acesso dos imigrantes aos direitos básicos [...] (INFORMATIVO, 2015).

Percebe-se, portanto, que existem alguns setores que preocupam mais os imigrantes haitianos. Entre essas problemáticas está a questão da moradia, onde os locatários necessitam de fiadores na lavratura do contrato e nem sempre encontrar esse fiador é fácil quando se trata de uma pessoa recém-chegada no País. Outra dificuldade é o emprego, o idioma e o acesso à educação, pois o valor das mensalidades dos cursos de nível superior torna o acesso inviável.

Além dos governos locais e estadual, o Governo Federal também aparece, uma vez que haitianos do Vale levaram demandas à Brasília. Os representantes Simon Renel e Edoarda Scherer estiveram com o então ministro da Secretaria Geral da Presidência da República, Miguel Rossetto. O encontro foi intermediado pela Rede Ecumênica da Juventude (Reju). Na ocasião foi entregue ao ministro, um manifesto que indica as principais dificuldades enfrentadas pelos imigrantes refugiados no Brasil, entre essas reivindicações estava a garantia de acesso a financiamentos estudantis e a agilidade na emissão de documentos (INFORMATIVO, 2015).

8 Luís Fernando Schmidt esteve à frente da Prefeitura de Lajeado no período de 2013 a 2016. 
Além do município de Lajeado/RS, outras cidades do Vale também estão desenvolvendo ações que visam o intercâmbio cultural. No dia 18 de setembro de 2017, a Escola Municipal de Educação Infantil Navegantes, de Encantado, reuniu pais, professores e funcionários para discutir junto à Secretaria Municipal de Educação estratégias para incluir de forma eficiente as crianças haitianas na rotina da comunidade escolar (INFORMATIVO, 2017).

\section{Considerações finais}

Os fluxos migratórios, tão conhecidos no campo da história, levantam uma série de inquietações e, de forma inconsciente, dividem as pessoas. Essa divisão, porém, é criada por ações humanas. Nesse sentido, os discursos oficiais e a imprensa possuem papel decisivo no sentido de influenciar a opinião pública.

A proposta da pesquisa, dessa maneira, foi analisar o discurso utilizado pela imprensa local para tratar da comunidade haitiana no Vale do Taquari. Para isso, foram analisadas 23 matérias publicadas pelo jornal $O$ Informativo do Vale entre os anos de 2012 e 2017. Examinando essas matérias, buscou-se compreender os pontos de vista veiculados pelo periódico de Lajeado/ RS a respeito da chegada e da presença de haitianos na Região9.

A análise das matérias habilita a elaboração de uma hipótese a respeito do discurso do jornal, que é a de que o diário constrói um discurso cultural, salientando particularidades da comunidade haitiana inseridas na Região.

No primeiro momento detalhamos os procedimentos metodológicos e o aporte teórico da pesquisa. Do ponto vista teórico, o tema é tratado como uma representação simbólica da realidade. E, metodologicamente, perseguem-se as orientações relativas ao uso da imprensa como fonte e objeto de estudo para a história. Sem esse aprofundamento teórico não seria possível estabelecer relações que comprovem a hipótese.

O jornal O Informativo do Vale circula em 38 municípios. O perfil jornalístico é caracterizado pelo conceito de jornalismo informativo moderno ${ }^{10}$, onde não existe um posicionamento claro por parte da instituição. O jornal, enquanto empresa de comunicação, firma contratos de prestação de publicidade para os mais diversos serviços e empresas. O segundo subtítulo mostra a estrutura do jornal enquanto empresa. Essa caracterização é importante, uma vez que aspectos jornalísticos adotados pelo diário devem atender a uma série de critérios, visto que a empresa responde a estímulos de mercado o que interfere no resultado das matérias.

Já o terceiro subtítulo examina matérias que trabalham questões socioculturais. Nota-se ao longo da pesquisa que a inclusão social é um fator muito problemático na Região, tendo em vista que a maioria das manifestações culturais são propostas pela iniciativa pública ou, então, por instituições privadas como a Univates. Não existe grande intercâmbio cultural, criam-se apenas grupos que expressam a sua cultura, mas muitas vezes apenas para os seus pares.

9 Do Vale do Taquari.

10 Conceito utilizado como aporte teórico. 
É importante que a representação simbólica seja interpretada com olhar crítico, uma vez que o jornal é um meio de comunicação de massa capaz de influenciar a opinião pública. $\mathrm{O}$ jornal O Informativo do Vale é um importante veículo influenciador na Região e está presente na cobertura de todos os acontecimentos de relevância regional.

Mesmo sendo O Informativo do Vale, um jornal que adota perfil de informativo moderno, caracterizado por Rüdiger (1995), não se pode tomar o discurso como verdade absoluta, uma vez que, enquanto empresa, os estímulos de mercado são levados em consideração no momento de publicar ou não certa informação. E, caso opte pela publicação, essa é feita de forma neutra, ficando a interpretação por conta do leitor.

A maior parte das matérias foi publicada no ano de 2015, foi nesse ano que as entidades locais passaram a debruçar-se mais com relação ao assunto da imigração. O periódico reservou um espaço significativo para essas questões e, por esse motivo, tornou-se uma importante fonte de pesquisa local.

\section{Referências}

BRAGA, José Luiz. Questões metodológicas na leitura de um jornal. O jornal: da forma ao sentido. Brasília: UNB, 2002. p. 321-334.

BOURDIEU, Pierre. A influência do jornalismo. In: BOURDIEU, Pierre. Sobre a televisão. Rio de Janeiro: Jorge Zahar, 1997.

CHARTIER, Roger. A história cultural: entre práticas e representações. Rio de Janeiro: Bertrand Brasil, 2003.

ELMIR, Cláudio Pereira. As armadilhas do jornal: algumas considerações metodológicas de seu uso para a pesquisa histórica. Cadernos do PPG em História da UFRGS, v. 13, p. 19-29, 1995. FÉLIX, Loiva Otero. História e Memória: a problemática da pesquisa. Passo Fundo: Ediupf, 1998. FOUCAULT, Michel. A arqueologia do saber. 7. ed. Rio de Janeiro: Forense-Universitária, 2004. GARRIDO, Joan del Alcazar. As fontes orais na pesquisa histórica: uma contribuição ao debate. Revista Brasileira de História, São Paulo, v. 13. n. 25/26, set. 1992.

GREGOLIN, Maria do Rosário. Análise do discurso e mídia: a (re)produção de identidades. Comunicação, mídia e consumo, São Paulo: v. 4, n. 11, p. 11-25, nov. 2007.

LE GOFF, Jacques. História e Memória. 5. ed. Campinas: UNICAMP, 2003.

MARTINO, C. Luiz. Comunicação e História: interfaces e novas abordagens. São Paulo: [s. n.], 2008. MEJÍA, Margarita Rosa Gravina; CAZAROTTO, Rosmari; GRANADA, Daniel. Migração Haitiana no Brasil: análise de um processo em construção a partir de um estudo de caso. Santa Cruz do Sul: UNISC, 2015. https://doi.org/10.11606/d.3.2007.tde-08012008-104811

MEJÍA, Margarita Rosa Gravina. Sonhos que mobiliza o imigrante haitiano: biografia de Renel Simon. Lajeado: Ed. da Univates, 2015. 48

MEZZAROBA, Oriedes; MONTEIRO, Cláudia Servilha. Manual de metodologia da pesquisa no direito. 2 ed. rev. São Paulo: Saraiva, 2004. 
RÜDIGER, Francisco R. Contribuição à História da Publicidade no Rio Grande do Sul. Revista Famecos, Porto Alegre, n. 3, p. 42-48, set. 1995. https://doi.org/10.15448/1980-3729.1995.3.2930 THOMPSON, John B. Ideologia e cultura moderna: teoria social crítica na era dos meios de comunicação de massa. 6. ed. Petrópolis: Vozes, 1995-2002.

THOMPSON, P. A voz do passado: História oral. Tradução de Lólio Lourenço de Oliveira. Rio de Janeiro: Paz e terra, 1992.

WILLIAMS, Raymond (org.). História de la comunicación: de la impreta a nuestros dias. Barcelona: Bosch Comunicación, 1992. In: RIBEIRO, Ana Paula Goulart. HERSCHMANN (org.). Comunicação e História: interfaces e novas abordagens. São Paulo: [s. n.], 2008.

ZICMAN, Renée Barata. História Através da Imprensa: Algumas Considerações Metodológicas. Revista História e Historiografia, São Paulo, p. 90., jun. 1985.

Recebido em: 26/8/2019.

Aprovado em: 3/10/2019.

\section{Willian Henrique Hoppe}

Endereço postal:

Instituição: Universidade do Vale do Taquari - UNIVATES

Av. Avelino Talini, 171, Bairro Universitário, Lajeado/RS

CEP: 95914-014 